\title{
The determination of values of the specific heat capacity of the selected thermal insulation materials used in track bed structure
}

\author{
Peter Dobeš ${ }^{1, *}$, Libor Ižvolt $^{1}$, Martin Mečár ${ }^{1}$, and Jana Malachová $^{2}$ \\ ${ }^{1}$ University of Zilina, Faculty of Civil Engineering, Department of Railway Engineering and Track \\ Management (DRETM), Univerzitná 8215/1, 01026 Žilina, Slovakia \\ ${ }^{2}$ University of Žilina, Institute of Continuing Education, Univerzitná 8215/1, 01026 Žilina, Slovakia
}

\begin{abstract}
The report concentrates on the determination of the specific heat capacity of the selected thermal insulation materials (liapor, styrodur, foam concrete). The aim of the report is to gain the necessary input parameters for the numerical modelling of the temperature changes of various track bed structures of the railway line where a part or, if appropriate, the whole protective layer is replaced by the material with better thermal insulation properties. There are described the methods for stating the specific heat capacity as well as the calibration of the calorimeter for stating of the calorimetric constant in the introduction of the report. The parameters needed for calculation of the specific heat capacity of the selected thermal insulation materials are characterized in the second part of the report. There are also introduced the laboratory stated values of the parameter in question. The comparison of the values stated by the laboratory measurements with the values introduced in the technical data sheets from their producers (or if appropriate gained from the foreign sources) is made in the conclusion of the report.
\end{abstract}

\section{Introduction}

The design and examination of the trackbed structure on the non-traffic load, related to numerical modelling of the frost penetration of the railway line structure (of the track bed), cannot be made without the basic input thermo-technical parameters of the built- in materials. Therefore, the most important characteristics are the heat conductivity coefficient $\lambda$ and the specific heat capacity $c$ of the building materials. The accepted EN STN do not introduce all the values of the thermal conductivity coefficients $\lambda$ and the specific heat capacity $c$ of the materials which are used in trackbed structure nowadays.

The design and examination of the trackbed structure of the railway lines is made according to TNŽ 736312 [1]. There are introduced the thermal conductivity coefficients $\lambda$ of various building materials used in the trackbed structure, in this legislative document. These coefficients are presented in the part concentrating on the design and examination of

*Corresponding author: dobes@,fstav.uniza.sk 
Railways of Slovak Republic on the non-traffic load. With regard to the necessity of amendment to the legislation document [1] and the updating of chart with the proposed values of the thermal conductivity coefficients $\lambda$ of the used building materials it is necessary to verify some of them and for some to determine new materials.

Since 1993 the Department of Railway Engineering and Track Management (DRETM) has been specialising in the problematics of the climatic parameters and the problematics of the frost penetration of the railway line structure. A mutual comparison of the results of frost penetration into the real models of the railway line structure with different material composition and the results obtained by numerical modelling of the models in question has been realised since 2009. The DRETM has been focusing on the problematics of the application of thermal insulation materials in the structure composition of the trackbed (where the thermal insulation material in question (structural element) replaces a part of protective layer) since 2016. There was proceeded an extension of the original experimental stand for monitoring the thermo-technical properties and penetration of the zero isotherm of the railway line structure (of the trackbed) in 2016. There was completed a measuring profile with the application of the thermal insulation layer to the measuring profiles which constituted the standard track bed structures. This experimental workplace, in a workrelated context referred to as "Experimental stand DRETM", consists of more measuring profiles nowadays and it will be completed within the year 2017.The first three measuring profiles represent the most frequently used railway line structures for modernisation of the railway infrastructure of Slovak Republic nowadays. The first profile is created by an embankment from the crushed aggregate of size fraction $0 / 63 \mathrm{~mm}$ without any protective layer. The second measuring profile forms an embankment with a protective layer from the crushed aggregate of size fraction $0 / 31.5 \mathrm{~mm}$ and the structural thickness $0.45 \mathrm{~m}$. The third measuring profile is a cutting with the protective layer from crushed aggregate of the same size fraction and structural thickness as in the second measuring profile. In the fourth profile was a part of the protective layer, the crushed aggregate of size fraction $0 / 31.5 \mathrm{~mm}$ and of construction thickness $0.30 \mathrm{~m}$, replaced by a layer of liapor of size fraction $0 / 16 \mathrm{~mm}$ and of construction thickness $0.10 \mathrm{~m}$.

The application of liapor in the structure composition of the track bed resulted from the fact, that the material in question has been used in embankments of traffic structures for several years. The use of liapor is relevant because of its small bulk density (the lightenance of the embankment in case of a poor supporting soil) and its excellent thermal insulation properties. However, liapor is not the only thermal insulation material which seems to be an appropriate structural element for the protection against the frost-susceptible subgrade in the track bed against the adverse frost effects. Therefore, there has been planned an extension of already existing Experimental stand DRETM to other two measuring profiles $\left(5^{\text {th }}\right.$ and $6^{\text {th }}$ measuring profile) this year. It is expected that there will be built-in and tested other thermal insulation materials in these measuring profiles. Specifically, there is expected to built-in slabs from styrodur and liapor bound by cement.

Unfortunately, the thermo-technical parameters (especially the specific heat capacity $c$ ) of the building materials in question are missing on the websites of producers or they are insufficiently introduced. Since these parameters are inevitable for the numerical modelling of the temperature development of railway line in the software Soilvision, it was necessary to determine them by laboratory tests. The modification of the procedure for measuring, calibration of the apparatus, as well as the measured parameters themselves, which are inevitable for determination of the specific heat capacity, are introduced in the following text. 


\section{Methodology for the determination of the specific heat capacity $c$ of the selected thermal insulation materials of the trackbed}

The application of the thermal insulation materials in the construction of the trackbed may seem irrelevant according to the predictions of the models concerning the climatic conditions. As according to the climatologists there is the assumption of the warming to continue, the annual average temperatures to grow and the snow cover to decrease. However, these climatic models do not exclude extreme winter periods - with longer and intense periods of frost and a reached high frost index-which can occur from time to time. The use of the thermal insulation materials is also supported by the fact, that the modernisation of main corridors of the railway lines in Slovakia approaches slowly the coldest areas of Slovakia (the regions of Low and High Tatras). Nowadays there have been reached the values of frost index close to the proposed values of the frost index which were defined for the territory of the Slovak Republic. The application of the heat insulation building materials into the structure of the railway line or the track bed can bring many advantages with itself. To these belong in particular the total heat protections of the frostactive soil against the adverse effects of frost while saving natural materials (crushed aggregate) because of the design with the lesser structural thickness of the frost protective layer.

The experimental measurements of the specific heat capacity $c$ and other parameters, which are necessary for the final determination of the thermal conductivity coefficient $\lambda$, have been realised in the laboratory of DRETM since 2008. The initial measurements of the parameters in question served especially to verify the parameters introduced in [1] and [2]. As mentioned above, nowadays the experimental measurements are concentrated on new building materials which could be applied in the structural composition of the railway line trackbed (e.g. liapor, styrodur, foam concrete, etc.). As the most important thermo-technical parameter - the thermal conductivity coefficient $\lambda-$ is well identified for the building materials in question, the experimental measurements were concentrated only on the determination of the specific heat capacity $c$ of the thermal insulation materials in question. This parameter is either unknown or insufficiently introduced but it is needed for the numerical modelling of the frost penetration of railway line structure (of the track bed).

\subsection{The adaptation of the equipment for determination of the specific heat capacity $c$}

The specific heat capacity $\left.c\left[\mathrm{~J}_{\mathrm{kg}} \mathrm{kg}^{-1} \cdot \mathrm{K}^{-1}\right)\right]$ of the monitored building materials is being determined by a calorimetric test. The precise determination of the specific heat capacity $c$ is represented by a complex laboratory process of defining the partial parameters which influence the overall results achieved. As the water, which surrounds the sample of the measured material, is the main medium for the calorimetric test and the thermal insulation materials have a smaller bulk density than water, it was necessary to adapt the structure of the calorimeter.

In contrast to the standard structure of the calorimeter it was necessary to fix a nylon thread to the inner walls of the calorimeter. The nylon thread not only keeps the sample under water during the entire process of measurement but it also prevents the test sample to be sucked into the stirrer. There were used plastic holders (plastic materials consume minimum heat) for fixing the nylon tread to the inner walls of the calorimeter. The further procedure remained unchanged where a polyethylene packaging was used to protect the sample against soaking. The sample was tempered to the temperature of the room (less than $20^{\circ} \mathrm{C}$ ) and the calorimetric test started at the temperature of the $+50{ }^{\circ} \mathrm{C} \pm 2{ }^{\circ} \mathrm{C}$ water. 
The specific heat capacity of a dry sample $c_{0}$ was calculated from the following relation on the basis of the experimentally stated parameters:

$$
c_{0}=\frac{m_{v} \cdot c_{v}+K}{m} \cdot \frac{\theta_{P}-\theta_{K}}{\theta_{K}-\theta}
$$

Where is: $\quad c_{0}$ - specific heat capacity of a dry sample, $[\mathrm{J} /(\mathrm{kg} . \mathrm{K})]$,

$m_{v}$ - water mass, $(\mathrm{kg})$,

$c_{v}$ - specific heat capacity of the water, $[\mathrm{J} /(\mathrm{kg} . \mathrm{K})]$,

$m$ - test sample mass, $(\mathrm{kg})$,

$\theta_{P}$ - initial temperature of the water, $\left({ }^{\circ} \mathrm{C}\right)$,

$\theta_{K}$ - final temperature of the system, $\left({ }^{\circ} \mathrm{C}\right)$,

$\theta$ - temperature of the sample before measurement, $\left({ }^{\circ} \mathrm{C}\right)$,

$K$ - heat capacity of the calorimeter, $\left(\mathrm{J} \cdot \mathrm{kg}^{-1}\right)$,

The recalculation of the specific heat capacity of the sample from the dry to the wet state was subsequently realised by means of the relation:

$$
c=c_{0}+\left(c_{v}-c_{0}\right) \cdot \frac{w_{m}}{100+w_{m}}
$$

Where is : $\quad c$ - specific heat capacity of a wet material, $[\mathrm{J} /(\mathrm{kg} . \mathrm{K})]$, $w_{m}$ - moisture content in the sample, (\%) [3].

Since the equipment for determination of the specific heat capacity $c$ was supplemented by other components, there was necessary a calibration of calorimeter what is introduced in the following part of the text.

\subsection{Calibration of calorimeter}

The experimental monitoring of the temperature decrease of the thermal insulation material (medium) within the calibration was carried out in the identical working procedure as the for the standard building materials of exceeding specific mass with the difference that there was used water as a sample (it has the biggest specific heat capacity from the common substances) with lower temperature than the medium has (less than $20{ }^{\circ} \mathrm{C}$ ). It should be emphasised that the sample of water was not inserted into the calorimeter in the polyethylene packaging but it was poured freely and the tempering of it to the temperature of the room was realised by placing it into the container with water. The resulting value of the heat capacity of the calorimeter was defined by deriving the parameter $\mathrm{K}$ from the relation (1).

Overall, there were realised 5 calibration measurements for calibration of the calorimeter where the water volume was about 10 litres in the calorimeter, its temperature was $50{ }^{\circ} \mathrm{C} \pm 2{ }^{\circ} \mathrm{C}$ and the mass of the test sample was from 500 to $700 \mathrm{~g}$. The determined values of the heat capacity $K$ are presented in Table 1 .

Table 1. Determined values of heat capacity $K$ of the calorimeter.

\begin{tabular}{|c|c|c|c|c|c|c|}
\hline $\begin{array}{c}\text { Number of } \\
\text { measurement }\end{array}$ & $\begin{array}{c}\text { Sample } \\
\text { temperature } \\
\boldsymbol{\theta} \\
\left({ }^{\circ} \mathrm{C}\right)\end{array}$ & $\begin{array}{c}\text { Water } \\
\text { temperature } \\
\boldsymbol{\theta}_{\boldsymbol{p}} \\
\left({ }^{\circ} \mathrm{C}\right)\end{array}$ & $\begin{array}{c}\text { Water } \\
\text { temperature } \\
\boldsymbol{\theta}_{\boldsymbol{k}} \\
\left({ }^{\circ} \mathrm{C}\right)\end{array}$ & $\begin{array}{c}\text { Water } \\
\text { mass } \\
\boldsymbol{m}_{\boldsymbol{v}} \\
(\mathrm{kg})\end{array}$ & $\begin{array}{c}\text { Sample } \\
\text { mass } \\
\boldsymbol{m} \\
(\mathrm{kg})\end{array}$ & $\begin{array}{c}\text { Heat } \\
\text { capacity } \\
\boldsymbol{K}\end{array}$ \\
\hline 1 & 13.48 & 48.27 & 46.37 & 10.221 & 0.595 & 330 \\
\hline 2 & 14.55 & 48.81 & 46.96 & 10.059 & 0.577 & 207 \\
\hline 3 & 15.15 & 49.15 & 47.11 & 10.635 & 0.683 & 274 \\
\hline 4 & 14.40 & 48.95 & 46.76 & 9.992 & 0.681 & 296 \\
\hline 5 & 13.95 & 47.15 & 45.46 & 10.502 & 0.568 & 331 \\
\hline
\end{tabular}


Subsequently, there was calculated, as an arithmetic average, the resulting value of the

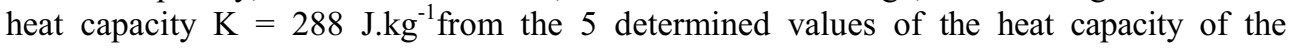
calorimeter. This heat capacity was further used for the calculation of specific heat capacity $c_{0}$ of other tested building materials.

\subsection{Determination of specific heat capacity of the selected materials}

The specific heat capacity is a quantity characteristic for the substance and it has for various substances and various forms various values. In general, this quantity specifies what amount of heat is to be added to a substance with the mass of one kilogram to increase its temperature in $1{ }^{\circ} \mathrm{C}$ or $1 \mathrm{~K}$. For all the substances remains the fact, that the specific heat capacity is being reduced by the decrease of the temperature, however, the reduction is not very big so it is possible to consider the values of specific heat capacity as constant for a certain temperature interval [4].

As mentioned in the introduction of this article, there were tested 3 thermal insulated building materials altogether, namely liapor of size fraction $0 / 16 \mathrm{~mm}$, styrodur and foam concrete, which are assumed to be built-in to other measuring profiles of the railway line model - of the Experimental stand DRETM.

\subsubsection{Determination of specific heat capacity of liapor of size fraction 0/16 $\mathrm{mm}$}

Liapor is lightweight clay aggregate which is produced by burning and expanding clay in rotary kilns at temperatures about $1200{ }^{\circ} \mathrm{C}$. There are created granules of pure natural material with excellent performance that is transferred also to other materials produced of it. Liapor, in the form of ceramic granules, is used in various grain sizes especially for different backfills and subbase where it performs a thermal insulation function. This material is used, because of its low specific weight, into the lightened embankments of line constructions abroad. The value of the thermal conductivity coefficient $\lambda$ of liapor is from 0.09 to $0.15 \mathrm{~W} \cdot \mathrm{m}^{-1} \cdot \mathrm{K}^{-1}$ depending on its specific weight.

The basic properties of liapor are: low specific weight $350-500 \mathrm{~kg} \cdot \mathrm{m}^{-3}$, heat conductivity from $0.10 \mathrm{~W} . \mathrm{m}^{-1} \cdot \mathrm{K}^{-1}$, high compressive strength, mechanical resistance, chemical stability, fire-resistance, low absorptivity, high soundness, without organic particles and foreign bodies, wholesomeness [5].

The value of specific heat capacity $c_{0}$ of liapor was defined from the measured parameters presented in Table 2, where are presented also its specific values for the individual measurements. There was created a sample of mass about $500 \mathrm{~g}$ for determination of the specific heat capacity $c_{0}$ of liapor. The sample was produced by mixing of size fraction $8 / 16$ and $0 / 4 \mathrm{~mm}$ in a ratio $1: 1$ (the same ratio was used also for the construction of the $4^{\text {th }}$ measuring profile of the Experimental stand DRETM.

Table 2. Determined values of the specific heat capacity $c_{0}$ of liapor of size fraction $0 / 16 \mathrm{~mm}$.

\begin{tabular}{|c|c|c|c|c|c|c|}
\hline $\begin{array}{c}\text { Number } \\
\text { of } \\
\text { measure- } \\
\text { ment }\end{array}$ & $\begin{array}{c}\text { Sample } \\
\text { temperature } \\
\boldsymbol{\theta} \\
\left({ }^{\circ} \mathrm{C}\right)\end{array}$ & $\begin{array}{c}\text { Water } \\
\text { temperature } \\
\boldsymbol{\theta}_{\boldsymbol{p}} \\
\left({ }^{\circ} \mathrm{C}\right)\end{array}$ & $\begin{array}{c}\text { Water } \\
\text { temperature } \\
\boldsymbol{\theta}_{\boldsymbol{k}} \\
\left({ }^{\circ} \mathrm{C}\right)\end{array}$ & $\begin{array}{c}\text { Water } \\
\text { mass } \\
\boldsymbol{m}_{\boldsymbol{v}} \\
(\mathrm{kg})\end{array}$ & $\begin{array}{c}\text { Sample } \\
\text { mass } \\
\boldsymbol{m} \\
(\mathrm{kg})\end{array}$ & $\begin{array}{c}\text { Spec. heat } \\
\text { capacity } \\
\boldsymbol{c}_{\boldsymbol{o}}\end{array}$ \\
\hline 1 & 13.00 & 47.30 & 46.98 & 10.882 & 0.500 & 864 \\
\hline 2 & 15.48 & 46.52 & 46.22 & 10.730 & 0.518 & 852 \\
\hline 3 & 15.20 & 48.70 & 48.36 & 10.403 & 0.519 & 866 \\
\hline 4 & 16.30 & 48.33 & 48.01 & 10.474 & 0.522 & 853 \\
\hline 5 & 16.48 & 46.37 & 46.07 & 10.469 & 0.519 & 862 \\
\hline
\end{tabular}

Subsequently, there was defined (as an arithmetic average) the resulting value of the specific heat capacity $c_{0}$ of liapor of size fraction $0 / 16 \mathrm{~mm}$ from the five measured values of the specific heat capacity. The resulting value is $c_{0}=860 \mathrm{~J} \cdot \mathrm{kg}^{-1} \cdot \mathrm{K}^{-1}$. 


\subsubsection{Determination of specific heat capacity of styrodur}

Excellent thermal insulation properties, variability of types, various compressive strength and edge performance make styrodur a very necessary and useable material in structural, underground and traffic building industry. Besides of the application for insulation of circumferential walls, roofs and ceilings it is possible to use it also as a frost protection in the road and railway construction. Styrodur is extremely hard extruded polystyrene produced from polystyrene granules by a physical change of form called extrusion. It is characterised by its high compressive strength - up to $700 \mathrm{kPa}$ according to the type by $10 \%$ compression. The heat conductivity coefficient of styrodur is $\lambda=0.03-$ $0.04 \mathrm{~W} \cdot \mathrm{m}^{-1} \cdot \mathrm{K}^{-1}[6]$.

The value of specific heat capacity of styrodur was defined from the measured parameters presented in Table 3, where are presented also its specific values for the individual measurements. There was created a sample of mass about $80 \mathrm{~g}$ and with dimensions about $150 \times 150 \times 100 \mathrm{~mm}$ for determination of the specific heat capacity of styrodur. The sample was cut out of a styrodur slab (STYRODUR $2800 \mathrm{C}$ ).

Subsequently, there was defined (as an arithmetic average) the resulting value of the specific heat capacity $c_{0}$ of styrodur from the five measured values of the specific heat capacity. The resulting value is $c_{0}=2051 \mathrm{~J} \cdot \mathrm{kg}^{-1} \cdot \mathrm{K}^{-1}$.

Table 3. Determined values of the specific heat capacity $c_{0}$ of styrodur.

\begin{tabular}{|c|c|c|c|c|c|c|}
\hline $\begin{array}{c}\text { Number } \\
\text { of } \\
\text { measure- } \\
\text { ment }\end{array}$ & $\begin{array}{c}\text { Sample } \\
\text { temperature } \\
\boldsymbol{\theta} \\
\left({ }^{\circ} \mathrm{C}\right)\end{array}$ & $\begin{array}{c}\text { Water } \\
\text { temperature } \\
\boldsymbol{\theta}_{\boldsymbol{p}} \\
\left({ }^{\circ} \mathrm{C}\right)\end{array}$ & $\begin{array}{c}\text { Water } \\
\text { temperature } \\
\boldsymbol{\theta}_{\boldsymbol{k}} \\
\left({ }^{\circ} \mathrm{C}\right)\end{array}$ & $\begin{array}{c}\text { Water } \\
\text { mass } \\
\boldsymbol{m}_{\boldsymbol{v}} \\
(\mathrm{kg})\end{array}$ & $\begin{array}{c}\text { Sample } \\
\text { mass } \\
\boldsymbol{m} \\
(\mathrm{kg})\end{array}$ & $\begin{array}{c}\text { Spec. heat } \\
\text { capacity } \\
\boldsymbol{c}_{\boldsymbol{\theta}}\end{array}$ \\
\hline 1 & 16.48 & 45.83 & 45.72 & 10.404 & 0.079 & 2090 \\
\hline 2 & 14.76 & 47.59 & 47.47 & 10.578 & 0.078 & 2087 \\
\hline 3 & 14.27 & 47.70 & 47.58 & 10.569 & 0.078 & 2051 \\
\hline 4 & 13.60 & 50.04 & 49.96 & 10.382 & 0.048 & 2007 \\
\hline 5 & 13.80 & 49.91 & 49.83 & 10.349 & 0.048 & 2019 \\
\hline
\end{tabular}

\subsubsection{Determination of specific heat capacity of foam concrete}

Foam concrete is a building material with a good mechanical strength, low thermal conductivity and simple but highly technological processing. It is produced by mixing of binder, water, ingredients and technical foam. Foam concrete contains closed air gaps by which is reached its low specific weight and saving of material inputs. The variability of properties and wet process of its production offer a wide range of uses of foam concrete for compensation layers, fillings of various "deaf" spaces and production of prefabricated panels and blocks. This material can have its application on the places with a low deformation resistance of subgrade as well as in the areas with great frost-penetration depth. There is used foam concrete of low bulk density in practice, however, generally it is possible to produce foam concrete with bulk density from 350 to $1200 \mathrm{~kg} . \mathrm{m}^{-3}$. On the bulk density and also moisture of the foam concrete depends its value of the thermal conductivity coefficient $\lambda$ which reaches the values from 0.1 to $0.4 \mathrm{~W} \cdot \mathrm{m}^{-1} \cdot \mathrm{K}^{-1}$ [7].

The value of specific heat capacity of foam concrete was defined from the measured parameters presented in Table 4, where are presented also its specific values for the individual measurements. There was created a sample of mass about $500 \mathrm{~g}$ for determination of the specific heat capacity $c_{0}$ of foam concrete. The sample had dimensions 100x100x100 mm and bulk density $500 \mathrm{~kg} \cdot \mathrm{m}^{-3}$.

Subsequently, there was defined (as an arithmetic average) the resulting value of the specific heat capacity of foam concrete from the five measured values of the specific heat capacity. The resulting value is $c_{0}=1118 \mathrm{~J} \cdot \mathrm{kg}^{-1} \cdot \mathrm{K}^{-1}$. 
Table 4. Determined values of the specific heat capacity $c_{0}$ of foam concrete.

\begin{tabular}{|c|c|c|c|c|c|c|}
\hline $\begin{array}{c}\text { Number } \\
\text { of } \\
\text { measure- } \\
\text { ment }\end{array}$ & $\begin{array}{c}\text { Sample } \\
\text { temperature } \\
\theta \\
\left({ }^{\circ} \mathrm{C}\right)\end{array}$ & $\begin{array}{c}\text { Water } \\
\text { temperature } \\
\theta_{p} \\
\left({ }^{\circ} \mathrm{C}\right)\end{array}$ & $\begin{array}{c}\text { Water } \\
\text { temperature } \\
\boldsymbol{\theta}_{\boldsymbol{k}} \\
\left({ }^{\circ} \mathrm{C}\right)\end{array}$ & $\begin{array}{c}\text { Water } \\
\text { mass } \\
\boldsymbol{m}_{\boldsymbol{v}} \\
(\mathrm{kg})\end{array}$ & $\begin{array}{c}\text { Sample } \\
\text { mass } \\
\boldsymbol{m} \\
(\mathrm{kg})\end{array}$ & $\begin{array}{c}\text { Spec. heat } \\
\text { capacity } \\
c_{0} \\
\left(\mathrm{~J} \cdot \mathrm{kg}^{-1} \cdot \mathrm{K}^{-1}\right)\end{array}$ \\
\hline 1 & 13.62 & 49.41 & 48.90 & 10.480 & 0.567 & 1127 \\
\hline 2 & 14.00 & 49.76 & 49.24 & 10.363 & 0.562 & 1148 \\
\hline 3 & 16.84 & 47.26 & 46.83 & 10.415 & 0.565 & 1115 \\
\hline 4 & 13.72 & 46.79 & 46.33 & 10.468 & 0.563 & 1106 \\
\hline 5 & 15.30 & 49.21 & 48.74 & 10.425 & 0.564 & 1095 \\
\hline
\end{tabular}

\section{Conclusion}

Thermal insulation building materials find their usage not only in the building industry but also in other various parts of industry. Thermal insulation materials are often used also in the structure composition of layers of linear traffic structures abroad. Also our legislative documents, involved in the design of structure composition of traffic structures, consider these materials. The aim is to increase the heat resistance of pavement structure or track bed. Nowadays an amendment to the legislative document shall be taken [1] which has been in force since 1988. There are not presented the thermal conductivity coefficients of all building materials which are (or can) be used in the trackbed layers in the part of dimensioning of the track bed structure on the non-traffic load. It is desirable to verify in this connection not only the thermal conductivity coefficients $\lambda$ of standard materials, but also of the ones which have a perspective to be used. The Experimental stand DRETM, which is represented by a model of a railway line on a scale $1: 1$, serves to verify this parameter within our research. There already is ( $4^{\text {th }}$ measuring profile) or is intended to be built-in $\left(5^{\text {th }}\right.$ and $6^{\text {th }}$ measuring profile) a thermal insulation layer in some parts of the track bed. In particular, there is assumed to use styrodur and liapor bound by cement. The verification of the temperature development and penetration of zero isotherm into the railway line structure (of the track bed) happens in two ways - by an experimental measurement of the relevant thermo-technical parameters on the real railway line structure, but also by a numerical modelling of the temperature development of the railway line structure in software SoilVision. It was essential to obtain the necessary input parameters, to which belongs also the special heat capacity of the individual materials, for the realisation of the experimental monitoring and also the numerical modelling.

The value of the specific heat capacity $c$ of the thermal insulation building materials is not as important to the final customers as the thermal conductivity coefficient $\lambda$. Because of this reason, it is often much more difficult or absolutely impossible to obtain these values. At DRETM (in response to the necessary amendment to the legislation document [1]) is paid attention to the verification of the thermal conductivity coefficients $\lambda$ of the materials used in the track bed layers of the railway line. For this verification and their calculation is necessary a partial parameter what is a specific heat capacity. The values of the specific heat capacity $c_{0}$ of the individual thermal insulation building materials and their comparison with the values from their producers or from foreign sources are presented in Table 5.

As is evident from Table 5, the difference between the laboratory defined specific heat capacity of the tested thermal insulation building materials and the specific heat capacity declared by producer or gained from foreign sources (foam concrete) is minimal. The biggest difference was identified in case of liapor. However, it is necessary to emphasise that the value defined by producer is allocated to the size fraction $8 / 16 \mathrm{~mm}$ but the tested sample in laboratory DRETM was of size fraction $0 / 16 \mathrm{~mm}$ (it was created by mixing of two fractions). 
Table 5. Measured values of the specific heat capacity $c$ and their comparison with the values from producer.

\begin{tabular}{|l|c|c|}
\hline \multicolumn{1}{|c|}{ Building material } & $\begin{array}{c}\text { Specific heat capacity } \boldsymbol{c}_{\boldsymbol{0}} \\
\text { (determined in the laboratory } \\
\text { Ǩ̌STH) } \\
\left(\mathrm{J}_{\mathrm{Zg}} \mathrm{kg}^{-1} \cdot \mathrm{K}^{-1}\right)\end{array}$ & $\begin{array}{c}\text { Specific heat capacity } \boldsymbol{c}_{\boldsymbol{o}} \\
\text { (technical data sheet of the } \\
\text { producer or foreign source) } \\
\left(\mathrm{J} \cdot \mathrm{kg}^{-1} \cdot \mathrm{K}^{-1}\right)\end{array}$ \\
\hline Liapor fr. 0/16 mm & 860 & $900[8]$ \\
\hline Styrodur 2800 C & 2051 & $2060[9]$ \\
\hline Foam concrete & 1118 & $900-1100[10]$ \\
\hline
\end{tabular}

The application of the thermal insulation materials in the structure composition of the railway line appears as undesirable based on the climatic models forecasting constant warming of climate and increase of the average annual temperatures. But at the same time the climatologists do not exclude winter seasons with intense and longer frost periods. In this connection, we have to respect the fact that we have regions in Slovakia where were and are likely to be reached high values of frost index (Podtatranský region, Orava, Kysuce). In response to the necessary modernisation of the railway infrastructure of Railways of the Slovak Republic, the building materials with better thermal insulation properties can find a real application in the track bed structure related to the modernisation of railway lines.

The presented results are the results of solving the VEGA grant project 1/0275/16 Optimization design of sleeper subgrade due to non-traffic load aspect.

\section{References}

1. TNŽ 73 6312, Design of subgrade construction layers, Standard of Slovak Railway (2005)

2. STN EN ISO 10 456, Construction materials and products. Hygrothermal properties. Tabulated design (calculated) values and procedures for the determination of declared and design values of thermal quantities (2007)

3. P. Dobeš, Optimization of the subgrade design for non-traffic load (Dissertation thesis), ). University of Žilina, Faculty of Civil Engineering, Department of Railway Engineering and Track Management (2015)

4. http://fyzika.jreichl.com/main.article/view/578-merna-tepelna-kapacita

5. http://finistav.sk/katalog/vyrobok/liapor

6. http://www.prespor.sk/content/view/id/55/tepelne-izolacie-xps-a-eps.html

7. http://www.sircontec.sk/penobetony-pbg

8. http://registrace.novazelenausporam.cz/vyhledavani/vyrobek/SVT3013/lehkekeramicke-kamenivo-liapor/

9. http://www.isover.sk/sites/isover.sk/files/assets/documents/styrodur_2800_c technicky list.pdf

10. http://www.jurnalteknologi.utm.my/index.php/jurnalteknologi/article/view/8374/5067 